\title{
ACTIVITIES AIMED AT FACILITATION OF COMPETITIVENESS IN THE LATVIAN AQUACULTURE SECTOR \\ Inese Biukšāne ${ }^{1}$
}

\begin{abstract}
Aquaculture belongs to the fisheries sector, which is evaluated as a highly productive, competitive and ecofriendly sector. The EU's and Latvia's economic breakthrough is related to the aquaculture sector. Participating in the establishment of the Common Fisheries Policy of the EU and using the support provided by the EU's financial instruments, have given the Latvian aquaculture sector wide opportunities in the facilitation of competitiveness. This paper will aim to evaluate the competitiveness of the Latvian aquaculture sector, providing suggestions for its further development. On the grounds of the Model of the Factors Influencing Competitiveness of the Fisheries Sector Cluster, Aquaculture Competitiveness Index and the offered types of strategies developed by the author, was evaluated and analyzed the competitiveness of Latvian aquaculture sector and provided suggestions for further development of the sector. Significance of the factors and their influence upon competitiveness was checked through Principal component and regression analysis. In the framework of the research was evaluated and analyzed the level of competitiveness in Latvian aquaculture sector, identified ensuring spheres influencing competitiveness and provided suggestions for further development of the sector. The methodology developed within this paper can be used for evaluation of competitiveness of fisheries and its sectors in different countries. The results of the research can be used in elaboration, planning and improvement of the common policy of the sector.
\end{abstract}

JEL Classification Numbers: O11, O21, Q01; DOI: http://dx.doi.org/10.12955/cbup.v6.1132

Keywords: aquaculture, competitiveness, growth, Latvia, strategy.

\section{Introduction}

The inland waters in Latvia occupy $4.1 \%$ of the state's land area (Agriculture Ministry, 2013). They consist of approximately 12.5 thousand rivers with a total length of 37.4 thousand $\mathrm{km}, 2256$ lakes with a total area of $\sim 100$ thousand ha and $\sim 800$ artificial water bodies (Agriculture Ministry, 2014). Latvia's most valuable resources consist of its large freshwater resources. The potential amount of exploitable potable underground water is evaluated to be 4.7 million $\mathrm{m}^{3}$ in 24 hours. In the earth entails are a number of underground water, and it is possible to use their resources in aquaculture. A territory of around 15-20 thousand $\mathrm{km}^{2}$ is evaluated as perspective for use of geothermal energy (Latvian Environment, Geology and Meteorology Centre, 2018). The resources of surface and underground waters available in Latvia are evaluated as qualitative and sufficient for the aquaculture business (Agriculture Ministry, 2013). As environmental pollution, unfavourable spawning conditions, intensive fishing and other factors have negative influence on the condition of fish stock and consequently the volume of the fish raw materials available in the Baltic Sea reduces every year, the role of aquaculture in the generation of alternative fish resources significantly increases (Finance Ministry, 2003).

In the Latvian aquaculture sector, the farming of fish and crustaceans is not only for commercial sales, one's own consumption and angling, but also for artificial reproduction and resource restocking purposes. Aquaculture products are bred in open ground ponds, natural flow-through basins and recirculation systems, the location of which do not have to be directly related to the availability of fresh water resources. In 2016, the volume of aquaculture product sales were 732 tons with a total market value of 1.84 million EUR, where $85 \%$ of the production came from open ground ponds, $11 \%$ from natural flow-through basins and $4 \%$ - from recirculation systems (Central Statistical Bureau, 2018). Since open ground ponds in local conditions are most suitable for the breeding of cyprinid fish, carps dominated the production offer at the market (with an average of $91 \%$ of the aquaculture production obtained in ponds) (Central Statistical Bureau, 2018). In Latvia, carp farming may be viewed as a traditional occupation, as the respective experience and knowledge about their farming has been accrued. Also, other kinds of fish, such as trout, sturgeon, tench, pike, crucian carp, sander, etc., are bred for commercial sales. Lately businessmen have started to also experiment with farming of other fish species. Recirculation systems are regarded as the most productive way of fish farming. Although the Latvian aquaculture sector is not big, in the world's aquaculture market it is considered to be a highly productive, competitive and eco-friendly sector (Agriculture Ministry, 2013; 2014). The EU's and Latvia's economic breakthrough is related to aquaculture sector (Agriculture Ministry, 2013).

\footnotetext{
${ }^{1}$ Riga Technical University, Institute of Agricultural Resources and Economics, inese.biuksane@inbox.lv
} 
Research aim - to evaluate the competitiveness of the Latvian aquaculture sector, providing suggestions for its further development. To assess the aim, the following work tasks were put forward: 1) to develop methodology for evaluation of competitiveness; 2) to evaluate the competitiveness of the Latvian aquaculture sector; and 3) to provide conclusions and suggestions. The elaborated methodology for evaluation of competitiveness, which may be used for the evaluation of fisheries in both Latvia and other countries. The following elaborated methodology can assist institutions involved in the establishment and implementation of fisheries' policy, and to develop, plan and improve the common policy of the sector more successfully.

Qualitative and quantitative research methods were used in the study, including general scientific research methods, statistical research methods, mathematical methods and sociological research methods. The author mostly applied the methods of analysis and synthesis in elaboration of conclusions and suggestions. Microsoft Excel, Microsoft PowerPoint, XLSTAT Premium, an IrfanView program, and Google questionnaire creation tools was used in the processing and analysis of the study results.

\section{Materials and methods}

A Model of the Factors Influencing the Competitiveness of the Fisheries Sector Cluster (Biukšāne, 2016) and a Fisheries Sector Cluster Competitiveness Index in order to evaluate competitiveness of Latvian fisheries was developed. The index is calculated on the grounds of 6 sub-indexes, awarding each of them weights of influence and calculating several groups of indicators. The influence weights of the sub-indexes were determined using an expert method and survey (Biukšāne, 2017b). In the framework of the expert method, 5 representatives of the institutions involved in creation of fisheries policy were interviewed. In turn, the survey results were obtained from $36 \%$ out of the 335 fishery companies in Latvia. To assess competitiveness, 22 indicators were selected which were transformed pursuant to min-max $[-5 ; 5]$ normalization.

The significance of factors influencing the competitiveness and their impact on competitiveness were evaluated using a Principal component and regression analysis.

In the framework of the Principal component analysis, multicollinearity (Pearson correlation coefficient), safety of analysis (Cronbach's alpha coefficient) (Cronbach, 1951) and adequacy of selection (Kaiser-Meyer-Olkin Test) (Kaiser, 1960) were checked. Pursuant to the Screen Plot there were factors identified from strong correlation to weak correlation in a dimension of certain correlations (factors, the eigenvalues of which in covariance matrix is $\geq 1$ ) (Cattell, 1966). Possibilities of inclusion of variables in the obtained factors were determined according to the Rotation Method and the Rotation converged in 5 iterations using Varimax with a Kaiser Normalization (Kaiser, 1958).

A regression analysis was performed using the Multicollinearity Statistics Method. Standard deviation - Std. Error, Coefficient of Determination - R-squared, Adjusted Coefficient of Determination Adjusted R-squared and margin of confidence interval - Lower 95\% and Upper 95\% in the framework of the analysis were calculated. Moreover, a number of statistical tests were carried out: Student's tdistribution, Fisher's exact test and Durbin-Watson test, et al.

There were several strategies determined for enhancement of competitiveness: penetration strategy $\left(C_{L(-0<)} ; G_{P(0 \leq)}\right)$, development strategy $\left(C_{L(-0<)} ; G_{P(>0)}\right)$, enlargement strategy $\left(C_{L(>0)} ; G_{P(0 \leq)}\right)$ and improvement strategy $\left(C_{L(>0)} ; G_{P(>0)}\right)$ (Biukšāne, 2017a).

The research was conducted for the period from 2005 to 2015. According to the developed methodology, the competitiveness of Latvian aquaculture sector was evaluated and suggestions are offered for its further development.

\section{Results and discussion}

The analysis showed that the correlation coefficients of several indicators are closely interrelated, this indicates to multicollinearity, thus providing an opportunity to unite the specific indicators into one factor. Internal consistency of the indicators is high (actual value of Cronbach's alpha coefficient $0,798 \geq$ critical value 0,700 ) and the chosen data array - adequate (Kaiser-Meyer-Olkin Test actual value $0,593 \geq 0,500$ acceptable value), this proves that the variables describing the factorial features are compatible. Four factors were identified with changeable eigenvalues $\geq 1$ and this explains $92 \%$ of 
total variability (Figure 1). Applying the Rotation Method and performing Varimax with a Kaiser Normalization, it was found that the indicators have different contributions in factor loadings, and consequently they should be combined into several factors.

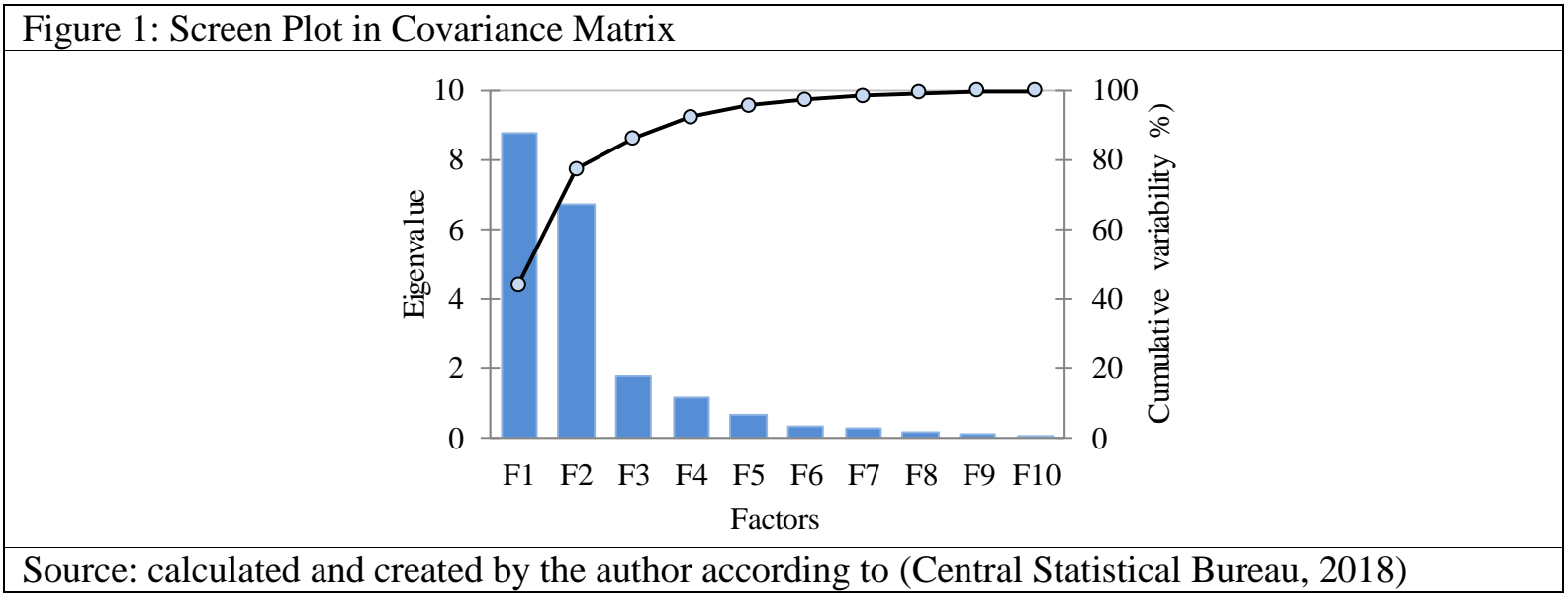

The variance of the effective feature can be explained by the linear influence of 4 factorial features: the volume of fish resources, the average salaries of the employees, the sales effectiveness coefficient and the overall liquidity ratio (Table 1). The linear influence of the other factorial features complies with the influence of the background.

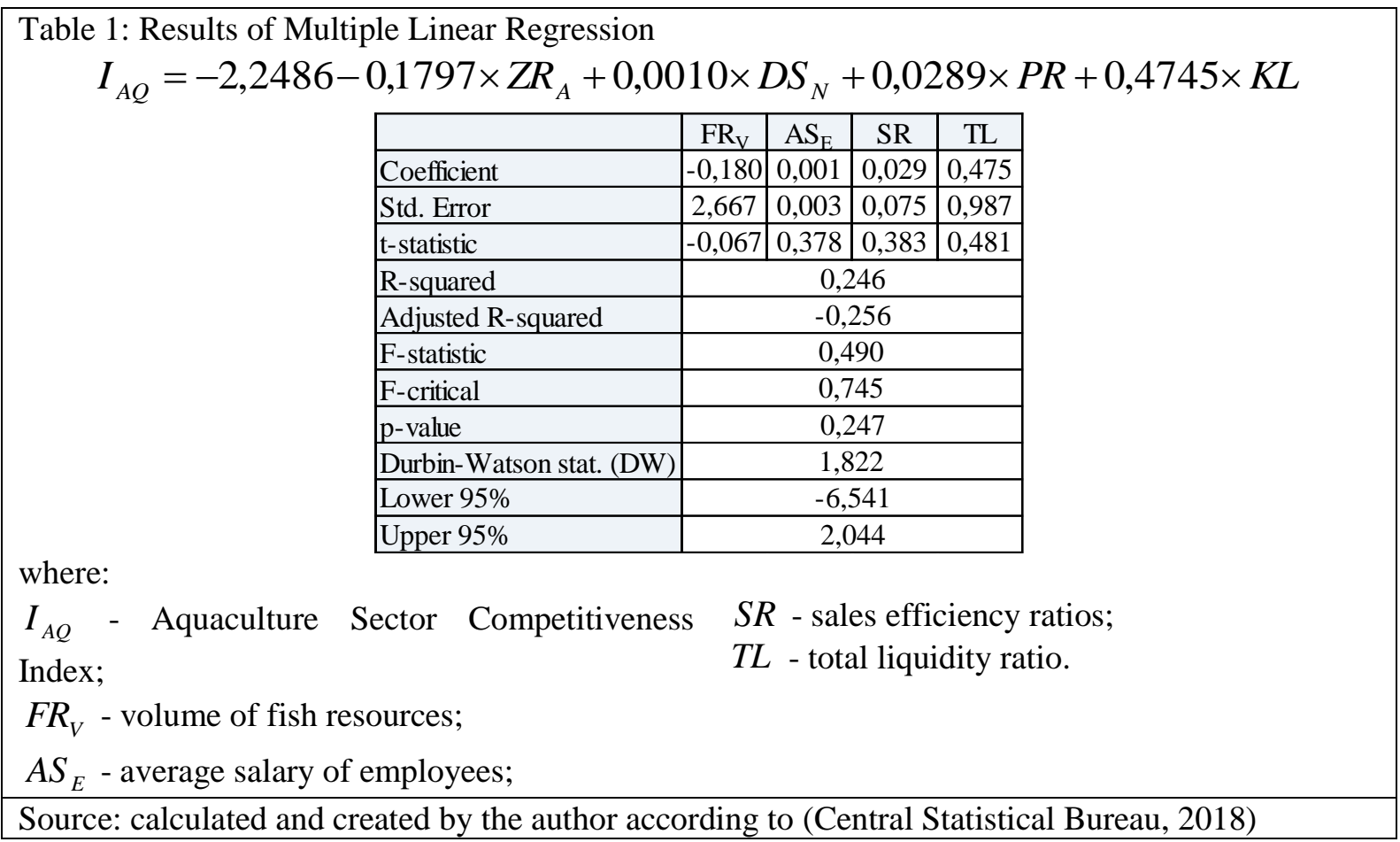

The results of the conducted analysis of causal relationships suggest that at the moment the variables that influence competitiveness can be evaluated as significant; however, it should be analyzed cautiously, this is because it is mostly determined by the comparatively small number of observations for a large number of independent variables. The obtained results of the analysis give a possibility to better understand the factors influencing the competitiveness and allow for the judgement of possibilities which can facilitate competitiveness.

The competitiveness of the Latvian aquaculture sector can evaluated as average to low (competitiveness from 2005 to 2015 deteriorated per -72\%) (Figure 2). The deterioration of competitiveness mainly is influenced by the stagnation of product competitiveness, the marketing and management efficiency, and the availability and quality of production factors. Currently the financial stability of the sector is the factor that enhances competitiveness. 


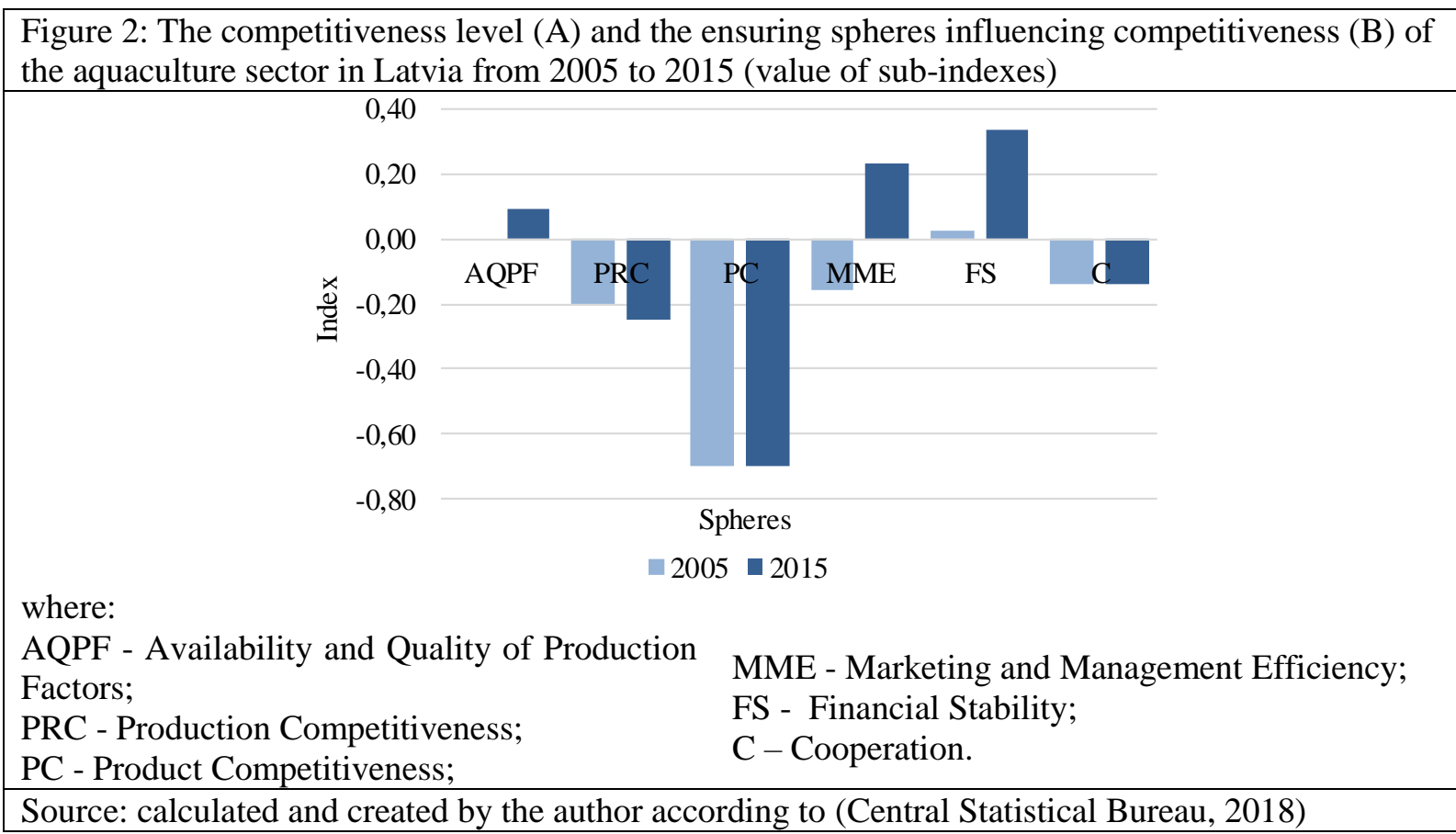

Enlargement strategy is suggested in order to facilitate the competitiveness of the aquaculture sector. In the framework of the strategy, the priority measures to be implemented are measures for the creation and strengthening of cooperation, and only then the facilitation of production and product competitiveness, the availability and quality of production factors, the marketing and management efficiency, and finally financial stability (Figure 3).

Figure 3: Measures for the facilitation of competitiveness in the Latvian aquaculture sector
Cooperation promotion and streng thening
- Improvement of Regulation of the Cabinet No.753
- Review of acknowiedgement criteria by producers' organizations
- Promotion of understanding of the importance of producers' organizations and their expedience
Production competitiv eness facilitation
- Balancing of fixed assets' capacity with production amounts
- Ensuring technical level
- Raising productivity of labour
- Full involvement of fixed assets and labour into production process, and rational and efficient use thereof
Product competitiveness fac litation
- Optimization of costs
- Production of products with high added value
Production factors rational and efficient use
- Facilitation of fish resource availability
- Productive use of real capital
- Increase in employees' salary
- Improvement and development of undertaking
Marketing and management efficiency facilitation
- Focus of measures on promotion of products in the market and advancement of sales
- Focus of measures on facilitation of successful business
Financial stability facilitation
- Rational and efficient use of support by the EU financial instruments
- Setting the ceiling for financial balance
- Advised and balanced structure of capital and distribution of financial resources
Source: created by the author


For the facilitation of competitiveness, it is recommended to create forms of tight cooperation and interaction with the institutions involved in the formation and implementation of fisheries policy, educational and scientific institutions, and other types of institutions, especially those involved in the generation of new ideas and the creation of innovations.

\section{Conclusion}

The elaborated methodology can be used for the evaluation of competitiveness of fisheries in Latvia and other countries, thus providing the institutions, involved in the establishment and the implementation of fisheries policy, an opportunity to develop, plan, and improve the common policy of fisheries more successfully.

The competitiveness of the Latvian aquaculture sector deteriorated from 2005 to 2015. The deterioration of competitiveness was influenced by the stagnation of product competitiveness and the availability and quality of production factors, this, in turn, reflected upon production competitiveness and the marketing and management policy. In the aquaculture sector a capital structure and the distribution of financial resources was successfully established, thus facilitating financial stability. Wide possibilities open up to the Latvian aquaculture sector for the facilitation of competitiveness and growth.

\section{References}

Agriculture Ministry. (2013). Akvakultūras daudzgadu stratēgiskās pamatnostādnes 2014. - 2020. gadam [Aquaculture multiannual strategic guidelines for 2014 - 2020]. Riga.

Agriculture Ministry. (2014). Ricibas programma zivsaimniecibas attīstībai 2014. - 2020. gadam [Operational Programme for Development of Fisheries 2014-2020]. Riga.

Biuksane I. (2016). Index of the Fisheries Sector Cluster Competitiveness: Internal factors. SGEM2016 Conference Proceedings, Book II, 4, 347-354. doi: 10.5593/SGEMSOCIAL2016/B24/S07.046.

Biukšāne I. (2017a). Competitiveness of the Blue Economy of Latvia. International Scientific Conference Engineering for Rural Development Proceedings, 16, 18-25.

Biuksane I. (2017b). The results of the Interviews and the Questionnaire given by the representatives of the institutions involved in the Latvian fisheries sector policy-making and implementation and the fisheries sector companies' (restricted access data).

Cattell R.B. (1966). The scree test for the number of factors. Multivariate Behavioral Research, 1(2), 245-276.

Central Statistical Bureau. (2018, January 15). Database [Web blog post]. Retrieved from

http://data.csb.gov.lv/pxweb/en/?rxid=cdcb978c-22b0-416a-aacc-aa650d3e2ce0 (restricted access data).

Cronbach J.L. (1951). Coefficient alpha and the internal structure of tests. Psychometrika, 16(3), 297-334.

Finance Ministry. (2003). Single Programming Document for Latvia. Objective 1 Programme 2004 - 2006. Riga.

Kaiser H.F. (1958). The varimax criterion for analytic rotation in factor analysis. Psychometrika, 23(3), 187-200.

Kaiser H.F. (1960). The application of electronic computers to factor analysis. Educational and Psychological Measurement, 20(1), 141-151.

Latvian Environment, Geology and Meteorology Centre. (2018, January 21). Groundwater [Web blog post]. Retrieved from http://www.meteo.lv/lapas/geologija/zemes-dzilu-resursi/pazemes-udeni/pazemesudeni?id=1236\&nid=491 